\title{
Dual Role of Th17 Cytokines, IL-17A,F, and IL-22 in Allergic Asthma
}

\author{
Bruno Schnyder and Silvia Schnyder-Candrian
}

\begin{abstract}
The proinflammatory role of T helper (Th) 17 cells and therefore of its cytokines, IL-17 (IL-17A), IL-17F, and IL-22, in autoimmune disorders has been favored, although there is evidence that not only IL-17A but also IL-17F and IL-22 have a dual role as negative regulators. Here we review the concept of the dual function of IL-17A, IL-17F, and IL-22 in the light of recent strategies to use neutralization of these cytokines as potential alternative to neutralizing TNF and IL-1 treatments in chronic inflammatory disorders. Expectedly, in allergic lung inflammation, neutralization of IL-17A inhibited neutrophil recruitment. However, this IL-17A antibody treatment concomitantly increased eosinophil recruitment by neutralizing IL-17A's dual role as negative regulator. IL-17A negatively regulated dendritic cell function and activation of T helper cell (Th)2 cytokine production. Furthermore, IL-17A inhibited Th2-characteristic chemokine and adhesion molecule expression. On a mechanistic level, IL-17A acted on I $\kappa$ B- $\beta$ by preventing degradation and in turn leading to reduced NF- $\kappa B$ activation or IL-17A inhibited transcription factor IRF-1. Therefore, anti-IL-17A therapy, although presenting a promising lead in chronic inflammatory disorders, bears a potential risk of exacerbating allergic asthma.
\end{abstract}

\section{IL-17A, IL-17F, and IL-22 Production by Antigen-Specific T Helper Th17 Cells Inhibits Th2 Response}

Interleukin-17A (IL-17A, aka IL-17) is the founding member of a multimember cytokine family consisting of IL-17A to IL-17F [1]. It forms homodimers containing five highly conserved cysteine residues forming a cysteine knot.

B. Schnyder $\bullet$ S. Schnyder-Candrian $(\bowtie)$

HES-SO, University of Applied Science, Sion, Switzerland

e-mail: sil.schnyder@bluewin.ch 
IL-17A and IL-17F homodimers and IL-17F/IL-17A heterodimer transduce their signals through the receptor composed of IL-17RA and IL-17RC [2, 3].

IL-17A and IL-17F are produced by the memory T cells termed Th17, a T helper cell lineage distinct from Th1 and Th2 cells, which is negatively regulated by interferon- $\gamma$ and IL-4 $[4,5]$. Unchecked activation of Th17 cells by IL-23 is linked to chronic inflammation in experimental autoimmune encephalomyelitis (EAE) and type II collagen-induced arthritis, two heretofore prototypical "Th1" disease models $[6,7]$.

The IL-23-Th17 cell axis has been implicated to contribute to the allergic Th2 response [8]; for review, see [9]. IL-23 as well as the co-expressed Th17 cells cytokines IL-17A and IL-22 [10] is found in the lung of allergic patients [11-13] and in lung homogenates of ovalbumin (OVA)-sensitized and challenged mice [8, 14]. In vitro production of IL-17A and IL-22 was triggered with IL-23 and even further enhanced in the presence of OVA, in cultures of mediastinal lymph node (MLN) cells isolated from antigen OVA-sensitized and challenged mice [8, 14]. Therefore, the role of IL-17A and IL-22 was addressed in the allergic response.

IL-17A was indeed required during antigen sensitization to develop a Th2 response in allergic asthma, as shown in IL-17R-deficient mice [8]. Neutralization of IL-17A, however in this model, augmented the allergic response, while recombinant IL-17A administration reduced pulmonary eosinophil recruitment and bronchial hyperreactivity. Recombinant IL-17A reduced eosinophil-chemokine eotaxin (CCL11) and thymus- and activation-regulated chemokine (TARC/CCL17) in lungs in vivo, and antigen uptake by dendritic cells and IL-5 and IL-13 production in regional lymph nodes were also reduced by recombinant IL-17A [8]. These findings demonstrated a novel negative regulatory role of IL-17A. A beneficial role of IL-17A has been confirmed in the model of chronic fungal-induced asthma. In this model, the protective role of TLR6 was dependent on IL-23 and the production of IL-17A. TLR6 deficient mice showed reduced IL-23 and IL-17A expression and an exacerbated Th2 response, which was normalized by addition of recombinant IL-23 which recovered the IL-17A production [15]. Furthermore, Murdoch and Lloyd provide evidence in the model of acute allergen-induced response that the $\gamma \delta \mathrm{T}$ cell-dependent normalization of lung function and resolution of inflammation was dependent on the production of IL-17 [16]. Therefore, endogenous IL-17A has a dual role. While it is essential during antigen sensitization to establish allergic Th2 response, in sensitized mice IL-17A attenuates the Th2 response.

A new role as negative regulator of antigen-driven Th2 response was ascribed for IL-17F. IL-17F dampened antigen activation of DCs resulting in a reduced Th2 response and reduced inflammation [14]. These findings may provide a possible explanation why Yang and colleagues found an increased allergic response in IL17F-deficient mice [17].

IL-22, similar to IL-17A [7, 18-20], has been found in diseased tissues from patients with different chronic inflammatory diseases, involving infiltrating activated $\mathrm{T}$ cells, such as rheumatoid arthritis, psoriasis, inflammatory bowel disease, and COPD [21-25]. IL-22 is expressed by IL-9-activated mast cell and by Th17 cells initiated by TGF- $\beta$ in the context of IL- 6 and other proinflammatory 
cytokines [10]. IL-22 is increased in lung homogenates of OVA-sensitized and challenged mice [14]. Neutralization of endogenous IL-22 in OVA-sensitized mice increased the eosinophilic response [14], whereas administration of recombinant IL-22 attenuated the acute allergic response [26, 27].

These data provide evidence that IL-17A,F and IL-22 besides their inflammatory role have a negative regulatory function in allergic lung inflammation.

\section{Increasing Evidence Supports This Novel Role of IL-17A and IL-22 as Down Modulators of a Committed Immune Response}

It has in the past abundantly been described that full acquisition of pathogenic function in experimental autoimmune encephalomyelitis (EAE) by effector Th17 cells is mediated by IL-23. However, as shown most recently, stimulation of the myelin-reactive $\mathrm{T}$ cells with TGF $\beta$ plus IL-6, instead of IL-23, completely abrogated their pathogenic function despite upregulation of IL-17A production [28]. These regulatory Th17 cells failed to upregulate the proinflammatory chemokines crucial for central nervous system inflammation. In contrast, the regulatory Th17 cells produced IL-10, which had potent anti-inflammatory activities. This study by Cua's group [28] did not show whether IL-17A directly conveyed negative regulation of inflammation, which was rather due to coexpressed IL-10 in EAE. Several experimental approaches listed below have indeed demonstrated direct inhibitory functions of recombinant and endogenously produced IL-17A in vitro and in vivo. Furthermore, an IL-17A-induced expression of the anti-inflammatory IL-10 has been demonstrated in macrophages, yet IL-17A has moderate effects on monocytes and macrophages [29].

First, expression of recombinant murine IL-17A in Vaccinia virus increased viral virulence significantly in mice [30], suggesting that IL-17A negatively regulated the antiviral host defense. Second, administration of recombinant IL17A ameliorated and negatively regulated the late phase of experimental autoimmune neuritis (EAN), a model of peripheral nerve demyelination [31]. Third, in vitro studies provided possible mechanisms of how IL-17A acts as a suppressor. IL-17A inhibited the chemokines RANTES (CCL5), Fractalkine (CX3CL1), and CTACK (CCL27) [32-34] and the mononuclear leukocyte adhesion molecule VCAM-1 in TNF-activated mesenchymal cells [35]. Fractalkine, CTACK, RANTES, and VCAM-1 are involved in inflammatory responses of both Th1 and Th2 types. RANTES and VCAM-1 are essential in the recruitment of mononuclear cells, and VCAM-1 is involved in the formation of germinal centers (present in autoimmunity). Therefore, existence of the novel negative regulatory role of IL17A needs to be revisited in multiple inflammatory and immune disorders.

Revisiting the role of IL-17A in multiple immune responses would help address the question as to whether IL-17A acts like a regulatory T cell (Treg) cytokine such as TGF $\beta$ or IL-10, which reduces allergic pulmonary challenges as well as vast $\mathrm{T}$ 
cell responses [36-38]. Indeed, in initial experiments IL-17A was described as a Treg cytokine in cell cultures, inhibiting vast $\mathrm{T}$ cell responses [36, 39]. Furthermore, Treg cells and TGF $\beta$ promote under proinflammatory conditions the development of Th17 cells and production of IL-17A [40]. Therefore, IL-17A as a downmodulator of the dendritic cells and Th2 response provides evidence for a novel feedback mechanism by which Treg cells may control a Th2 response in the effector phase of allergic asthma.

Protective role of IL-22 has also been ascribed in other models than allergic lung inflammation. IL-22 provided protection to hepatocytes during acute liver inflammation [41] and protected against ConA- or tetrachloride-induced liver injury [42]. Second, delivery of IL-22-Ig fusion gene ameliorated experimental autoimmune myocarditis (EAM) in rats [43]. Third, local IL-22 gene delivery led to rapid amelioration of intestinal inflammation in a mouse model of ulcerative colitis, and conversely, inhibition of IL-22 activity by local overexpression of its antagonist, IL-22 binding protein, prevented recovery and goblet cell restitution in acute colitis (DSS) [44]. Therefore, even though IL-22 is an upregulator of proinflammatory gene expression and has proinflammatory function, there is growing evidence that IL-22 has, similar to IL-17A, a protective role in inflammatory diseases such as colitis, EAE, and allergic lung inflammation.

\section{Excess Endogenous IL-17A and IL-22 Production in the Absence of IL-4 Signals In Vitro and In Vivo}

IL-17A production is induced by TGF $\beta$ in a proinflammatory milieu, including presence of IL-6, IL-1, or TNF, and its production is sustained by IL-23. In contrast, IL-17A production is inhibited by IL-4, IFN $\gamma$, IL-25 (IL-17E), or IL-27. In lungs, IL-17A has been shown to originate from antigen-specific Th17 cells as well as from an iNKT subpopulation, which is NK1.1 negative [45]. In an allergic lung response, IL-17A production was induced by IL-23 and controlled by IL-4 receptor signaling [8]. In mice lacking IL-4 responsiveness, IL-17A was overproduced correlating with reduced effector functions of allergic asthma. The inhibition of the Th2 response was indeed ascribed to endogenous IL-17A, as assessed using IL17A neutralizing antibody treatment in vivo.

In the absence of IL-4 responsiveness, not only IL-17A but also IL-22 production was significantly increased upon allergen challenge, and similar to IL-17A, inhibition of endogenous IL-22 by neutralizing antibodies increased the allergic response, indicating that both IL-17A and IL-22 contribute to the inhibition of the Th2 response.

This increase in IL-17A and IL-22 in the absence of IL-4 responsiveness was not due to differences in IL-23 concentrations since pulmonary OVA-induced IL-23 concentrations are equal in IL-4R $\alpha$ KO and WT mice [8]. Therefore, the IL-4 signals affect directly IL-22 and IL-17 production and do not act on IL-23 
production [8]. However, the molecular mechanism of IL-22 expression, being either IL-23 dependent or independent, in allergic lung inflammation needs to be investigated in future experiments.

Neutrophil involvement has been ascribed to both infectious disease and allergic inflammation [46-48]. In allergy, neutrophil recruitment is in part due to endogenous IL-17 [8, 49], but not due to IL-22, since neutralization of IL-22 did not diminish neutrophil but increase recruitment in the allergic response. This is in line with a previous report, which demonstrated that IL-22 alone and in synergy with IL10 decreased IL-8 production by human alveolar epithelial cell lines [50].

Therefore, a novel mechanism of how IL-4 promotes a Th2 response was proposed, by suppression of the novel suppressor molecules IL-17A and IL-22. This added a novel function of IL-4 to the list of its proallergic effects, including differentiation of Th2 lymphocytes, inhibition of T lymphocyte apoptosis, induction of $\operatorname{IgE}$ production, promotion of eosinophil transmigration into the lungs, mucus hypersecretion, and bronchoconstriction [8, 51-53].

\section{Molecular Mechanism of Negative Regulatory IL-17A and IL-22 Effects}

On a mechanistic level, IL-17A elicits dual effects and reportedly promotes expression of proinflammatory (hemopoietic, CXC-chemokines, acute phase) factors [54, 55], whereas it inhibits the production of mononuclear cell recruiting molecules like TNF-induced VCAM-1 and CC-chemokine RANTES [35]. This dual effect of IL-17A in human cell cultures predicted a reduced mechanism of mononuclear cell recruitment in vivo. CC-type chemokines RANTES (CCL5), TARC (CCL17) and eotaxin (CCL11) were induced by antigen OVA in vivo. TARC primarily attracts CCR4-positive Th2 cells. IL-17A reduced TARC production, which correlated with reduced lymphocyte counts and Th2-derived IL-5 concentrations in lung tissues. The expression of the major eosinophil attractant, eotaxin, was also reduced by IL17A and accompanied by reduced eosinophil infiltration in the airways. Indeed, reductions or absence of these $\mathrm{CC}$ chemokines reportedly ablates allergic asthma [56-58]. Therefore, diminished cell attraction seems to be the pivotal mechanism of how IL-17A attenuates the allergic inflammation.

Further IL-17A effects like acute phase IL-6 and prostaglandin (PG)E2 elevations may also have corroborated to reduce locally the allergic inflammation in the lungs. IL-6 elevations inhibited aeroallergen-induced Th2 inflammation [59, 60]. PGE2 elevations reduced pulmonary allergy specifically via the E3 receptor [61]. Therefore, while IL-17A may upregulate negative regulators IL-6 and PGE2, it has a direct inhibitory effect on the local production of Th2 cytokines IL-4, IL-13, and IL-5 in the lung and regional lymph nodes [8]. Mechanistically, IL-17A inhibits dendritic cell activation and antigen uptake, which leads to reduced activation of $\mathrm{T}$ cells and reduced IL-4, IL-13, and IL-5 production, resulting in reduced allergic response. 
However, the inhibition of the Th2 response by IL-17A represented a reduction rather than a complete blockade. Intact anti-allergen IgE concentrations in the circulation may explain why IL-17A did not completely block but rather reduced pulmonary allergy and asthma. Elevated IgE concentrations reportedly correlate with and contribute to allergic reactions [62], although it is not sufficient for the development of allergy. Therefore, IL-17A acts as negative regulator of established Th2 response locally in lungs.

In the experimental models of allergic lung inflammation, IL-22 dampened the hallmarks of an allergic Th2 response in vivo, by inhibition of DCs and their expression of co-stimulatory molecules upon antigen treatment [14]. IL-22 attenuates further the allergic response by inhibiting the induction of TARC (CCL17), IL-13 and IL-25 as shown in vivo [26, 27]. In vitro, IL-22 prevented TNF- $\alpha /$ IL-13-induced TARC and IL-13 production in murine Clara cells [26] and IL-25 production in the lung epithelial cell line MLE-15 induced by IL-1 $\beta$ or LPS [27]. Therefore, these data corroborate that IL-22 not only has a negative regulatory function in experimental models of autoimmunity, and inflamed liver and colon but also in established $\mathrm{Th} 2$ response in the lung.

\section{High Efficiency of Inhibitory Function of IL-17A In Vivo and In Vitro}

Intranasal administration of recombinant IL-17A reduced eosinophil recruitment and a Th2 response, while neutrophil recruitment was not induced when applied locally at low doses of $2.5 \mu \mathrm{g} / \mathrm{kg}$ IL-17A to allergen-treated mice [8]. These findings were supported by the following cell culture data [35]. IL-17A inhibited TNF-induced chemokine RANTES expression in human synovial fibroblasts and mouse lung fibroblasts. This inhibitory activity of IL-17A was sixfold more potent than its stimulatory activity on TNF- $\alpha$-induced IL-6 or IL-8 secretion (IC50 $=0.2$ $\mathrm{ng} / \mathrm{ml}$ vs. ED50 = $1.2 \mathrm{ng} / \mathrm{ml}$ ), measured in the same cells. Furthermore, neutralization of the human IL-17A receptor (IL-17R) by antibodies competitively reversed the IL-17A-induced IL-6 upregulation. However, anti-IL-17R antibody only partially neutralized the inhibitions of RANTES production by IL-17A. Yet, IL-17R was essential for the RANTES inhibition, as assessed in IL-17R-deficient cells. Therefore, inhibitory and stimulatory functions of IL-17A involve receptor IL-17R but show distinct dose responses and in turn different sensitivities to an IL-17R antagonizing antibody. These findings suggest a higher efficiency of the inhibitory over the stimulatory IL-17A functions and may explain why a net negative regulatory effect of IL-17A manifests in chronic inflammation in vivo where IL-17A production is low. 


\section{Molecular Signaling of Inhibitory Effects of IL-17A and IL-22}

IL-17A interferes at TNF-activated NF- $\kappa \mathrm{B}$ signaling in human synoviocytes [35]. This inhibition is immediate, within $20 \mathrm{~min}$, and proposes a direct effect of IL-17A rather than via expression of secondary mediators. The reduced degradation of specifically I $\mathrm{I} \mathrm{B}-\beta$, but not I $\mathrm{KB}-\alpha$, provides a late inflammatory phase control mechanism by IL-17A for the following reason. It has been shown that inhibitor I $\kappa \mathrm{B}-\alpha$ is of importance for the transient inactivation of $\mathrm{NF}-\kappa \mathrm{B}$, whereas $\mathrm{I} \kappa \mathrm{B}-\beta$ as part of a multimeric complex is involved in the persistent inactivation of NF- $\kappa \mathrm{B}$ $[63,64]$. The fact that I $\kappa \mathrm{B}-\beta$ but not I $\kappa \mathrm{B}-\alpha$ is affected by IL-17A further supports the possibility that IL-17A is implicated in the regulation of the chronic phase of inflammation and immunity.

However, interferences of IL-17A on TNF-induced NF- $\kappa \mathrm{B}$ activity virtually depend on the cell type and promoter targeted by TNF. For example, unlike the synoviocytes described above [35], TNF-induced NF- $\kappa$ B binding was only moderately and not statistically significantly reduced by IL-17A in colonic myofibroblasts [32]. In those cells, it was proposed that IL-17A interfered at the TNF-induced RANTES production mainly through inhibition of IRF-1. This in turn prevented the cooperation of IRF-1 with the NF- $\mathrm{B}$ activity.

Furthermore, in macrophages it has been shown that IL-17A inhibited TNF expression transiently, the effect of IL-17A being biphasic with an early decrease of TNF release (at less than $30 \mathrm{~min}$ ) and a marked stimulation later on (by $6 \mathrm{~h}$ ) [29]. After $60 \mathrm{~min}$ and later, IL-17A also inhibited cAMP production and the transcription factor activities of CREB, AP-1, as well as NF- $\mathrm{BB}$ in the macrophages [29].

IL-22, on the molecular and cellular level, acts by activating STAT3. In vitro stimulation of epithelial cell with IL-22 resulted in the phosphorylation of STAT3, and diminished TNF/IL-13 induced TARC and IL-13 production [26]. Beneficial effect of IL-22 through STAT3 activation has previously been published. So IL-22 enhanced hepatocyte survival, by enhancing expression of transcription factor STAT3, Bcl-2, and Bcl-xL in inflamed liver and colon [41, 42]. STAT3 activation in intestinal epithelial cells and IL-22 was linked to mucosal wound healing [65]. IL-22 activated STAT3 and induced IL-10 by colon epithelial cells [66]. Prevention of DC activation and antigen (OVA) sensitization induced by transfer of ex vivo OVA-loaded DC has previously been ascribed to the prototype immune regulator IL-10 [25] and newly for IL-22 [14]. Whether the negative regulatory effects of IL22 in allergic lung inflammation are due to IL-22 or indirectly induced needs further investigation.

\section{IL-17 and IL-22 Have Similar Effects in Allergic Lung Inflammation but Are Still Distinct}

The Th17-derived IL-22 and IL-17A negatively regulated allergy and DC functions. Its expressions were further induced by allergic stimulation together with IL-23 and were controlled by IL-4R $\alpha$ signals. While neutralizing IL-22 or 
IL-17 antibodies augmented the allergic response, IL-22, IL-17A, and IL-17F reduced the response by inhibiting DC functions. Therefore, the data demonstrate that IL-22 and IL-17 are novel endogenous negative regulators of allergy, and IL22, IL-17, or Th17 cells may represent an interesting therapeutic target in lung allergy.

IL-17A and IL-22 are both co-expressed in Th17 cells [10], yet they are induced through independent pathways. Recent studies showed that IL-22 but not IL-17A and IL-17F production strongly depends on aryl hydrocarbon receptor signals [67].

Furthermore, IL-22 production is induced in absence of IL-6, while IL-17A production depends on the presence of IL-6 [22]. Additional IL-22 production is ascribed to IL-9 activated mast cells [68]. We found that IL-17A, but not IL-22 production, was markedly dependent on the intracellular signaling of the IL-1 receptor and its adaptor MyD88 pathway in lymph node cell cultures originating from OVA-treated mice [14]. A review by Eyerich and colleagues provides an overview on overlaps and differences between IL-17 and IL-22 [69]. Together this suggests collaborative and nonredundant pathways leading to Th17 cytokines and allergy.

\section{Anti-IL-17 and Anti-IL-22 Therapies: A Risk or Advantage?}

The pathological role of IL-17A, IL-17F, and IL-22 in autoimmune disorders has convincingly been documented and hence favored so far, although there is emerging evidence that IL-17A, IL-17F, and IL-22 also have a beneficial role as negative modulator in antigen-specific immune processes and allergic asthma [8, 14, 26-28, 31].

Increased IL-17A concentrations in allergic asthma, chronic bronchitis, chronic obstructive pulmonary disease (COPD), cystic fibrosis, and acute respiratory distress syndrome (ARDS) (for review, see [11]), but also rheumatoid arthritis (RA), were linked to the pathology of the diseases [20]. IL-17A neutralization inhibits experimental murine arthritis [20] and is a potential alternative therapy to TNF neutralization in rheumatoid arthritis. The novel negative regulatory function of IL17A indicates, however, that such a therapy bears the potential risk of exacerbating allergic asthma. Therefore, an anti-IL-17A treatment in chronic inflammatory disorders seems very promising, inhibiting neutrophil recruitment in inflamed lungs and joints, while the exacerbating Th2 response in experimental allergic response by anti-IL-17A antibodies may exclude respective groups at risk from such a therapeutic anti-IL-17A treatment.

Because of the proinflammatory function of IL-17A and IL-22, neutralizing therapies targeting either IL-17 or IL-22 are considered in allergic asthma [70, 71]. However, inhibiting IL-17A or IL-22 may bear the potential risk of opportunistic infections. IL-22 together with TNF- $\alpha$ was found to be important to keep the epidermal integrity during infection with Candida albicans [72]. Mutations in STAT3 in animal models and humans confer a defect in IL-17 function, resulting 
in increased susceptibility to respiratory infections with bacteria and fungi $[70,73$, 74]. Neutralization of IL-22 resulted in exacerbation of bacterial infections, suggesting a protective role in mucosal/epithelial host defense [75]. And IL-22 was protective during the development of lung fibrosis induced by chronic exposure to Bacillus subtilis [76].

Still, because of the novel function of IL-22 and IL-17 as endogenous negative regulators of allergy, IL-22, IL-17, or Th17 cells may represent an interesting therapeutic target in lung allergy.

\section{References}

1. Fossiez F, Banchereau J, Murray R, Van Kooten C, Garrone P, Lebecque S (1998) Interleukin17. Int Rev Immunol 16(5-6):541-551

2. Toy D, Kugler D, Wolfson M, Vanden Bos T, Gurgel J, Derry J, Tocker J, Peschon J (2006) Cutting edge: interleukin 17 signals through a heteromeric receptor complex. J Immunol 177:36-39

3. Wright JF, Bennett F, Li B, Brooks J, Luxenberg DP, Whitters MJ, Tomkinson KN, Fitz LJ, Wolfman NM, Collins M, Dunussi-Joannopoulos K, Chatterjee-Kishore M, Carreno BM (2008) The human IL-17F/IL-17A heterodimeric cytokine signals through the IL-17RA/IL17RC receptor complex. J Immunol 181(4):2799-2805

4. Harrington LE, Hatton RD, Mangan PR, Turner H, Murphy TL, Murphy KM, Weaver CT (2005) Interleukin 17-producing CD4+ effector T cells develop via a lineage distinct from the T helper type 1 and 2 lineages. Nat Immunol 6:1123-1132

5. Park H, Li Z, Yang XO, Chang SH, Nurieva R, Wang YH, Wang Y, Hood L, Zhu Z, Tian Q, Dong C (2005) A distinct lineage of CD4 T cells regulates tissue inflammation by producing interleukin 17. Nat Immunol 6:1133-1141

6. Murphy CA, Langrish CL, Chen Y, Blumenschein W, McClanahan T, Kastelein RA, Sedgwick JD, Cua DJ (2003) Divergent pro- and anti inflammatory roles for IL-23 and IL12 in joint autoimmune inflammation. J Exp Med 198(12):1951-1957

7. Cua DJ, Sherlock J, Chen Y, Murphy CA, Joyce B, Seymour B, Lucian L, To W, Kwan S, Churakova T, Zurawski S, Wiekowski M, Lira SA, Gorman D, Kastelein RA, Sedgwick JD (2003) Interleukin-23 rather than interleukin-12 is the critical cytokine for autoimmune inflammation of the brain. Nature 421:744-748

8. Schnyder-Candrian S, Togbe D, Couillin I, Mercier I, Brombacher F, Quesniaux V, Fossiez F, Ryffel B, Schnyder B (2006) Interleukin-17 is a negative regulator of established allergic asthma. J Exp Med 203:2715-2725

9. Nakajima H, Hirose K (2010) Role of IL-23 and Th17 cells in airway inflammation in asthma. Immune Netw 10(1):1-4

10. Liang SC, Tan XY, Luxenberg DP, Karim R, Dunussi-Joannopoulos K, Collins M, Fouser LA (2006) Interleukin (IL)-22 and IL-17 are coexpressed by Th17 cells and cooperatively enhance expression of antimicrobial peptides. J Exp Med 203:2271-2279

11. Linden A, Adachi M (2002) Neutrophilic airway inflammation and IL-17. Allergy 57:769-775

12. Wong CK, Lun SW, Ko FW, Wong PT, Hu SQ, Chan IH, Hui DS, Lam CW (2009) Activation of peripheral Th17 lymphocytes in patients with asthma. Immunol Invest 38(7):652-664

13. Zhao Y, Yang J, Gao YD, Guo W (2010) Th17 immunity in patients with allergic asthma. Int Arch Allergy Immunol 151(4):297-307

14. Schnyder B, Lima C, Schnyder-Candrian S (2010) Interleukin-22 is a negative regulator of the allergic response. Cytokine 50(2):220-227 
15. Moreira AP, Cavassani KA, Ismailoglu UB, Hullinger R, Dunleavy MP, Knight DA, Kunkel SL, Uematsu S, Akira S, Hogaboam CM (2011) The protective role of TLR6 in a mouse model of asthma is mediated by IL-23 and IL-17A. J Clin Invest 121(11):4420-4432

16. Murdoch JR, Lloyd CM (2010) Resolution of allergic airway inflammation and airway hyperreactivity is mediated by IL-17-producing \{gamma $\{$ delta $\}$ T cells. Am J Respir Crit Care Med 182(4):464-476

17. Yang XO, Chang SH, Park H, Nurieva R, Shah B, Acero L, Wang YH, Schluns KS, Broaddus RR, Zhu Z, Dong C (2008) Regulation of inflammatory responses by IL-17F. J Exp Med 205:1063-1075

18. Hofstetter HH, Ibrahim SM, Koczan D, Kruse N, Weishaupt A, Toyka KV, Gold R (2005) Therapeutic efficacy of IL-17 neutralization in murine experimental autoimmune encephalomyelitis. Cell Immunol 27:27

19. Lubberts E, Schwarzenberger P, Huang W, Schurr JR, Peschon JJ, van den Berg WB, Kolls JK (2005) Requirement of IL-17 receptor signaling in radiation-resistant cells in the joint for full progression of destructive synovitis. J Immunol 175:3360-3368

20. Koenders MI, Lubberts E, Oppers-Walgreen B, van den Bersselaar L, Helsen MM, Di Padova FE, Boots AM, Gram H, Joosten LA, van den Berg WB (2005) Blocking of interleukin-17 during reactivation of experimental arthritis prevents joint inflammation and bone erosion by decreasing RANKL and interleukin-1. Am J Pathol 167:141-149

21. Wolk K, Kunz S, Witte E, Friedrich M, Asadullah K, Sabat R (2004) IL-22 increases the innate immunity of tissues. Immunity 21:241-254

22. Zheng Y, Danilenko DM, Valdez P, Kasman I, Eastham-Anderson J, Wu J et al (2007) Interleukin-22, a $\mathrm{T}(\mathrm{H}) 17$ cytokine, mediates IL-23-induced dermal inflammation and acanthosis. Nature 445:648-651

23. Andoh A, Zhang Z, Inatomi O, Fujino S, Deguchi Y, Araki Y et al (2005) Interleukin-22, a member of the IL-10 subfamily, induces inflammatory responses in colonic subepithelial myofibroblasts. Gastroenterology 129:969-984

24. Ikeuchi H, Kuroiwa T, Hiramatsu N, Kaneko Y, Hiromura K, Ueki K, Nojima Y (2005) Expression of interleukin-22 in rheumatoid arthritis: potential role as a proinflammatory cytokine. Arthritis Rheum 52:1037-1046

25. Koya T, Matsuda H, Takeda K, Matsubara S, Miyahara N, Balhorn A, Dakhama A, Gelfand EW (2007) IL-10-treated dendritic cells IL-10-treated dendritic cells decrease airway hyperresponsiveness and airway inflammation in mice. J Allergy Clin Immunol 119:1241-1250

26. Taube C, Tertilt C, Gyülveszi G, Dehzad N, Kreymborg K, Schneeweiss K, Michel E, Reuter S, Renauld JC, Arnold-Schild D, Schild H, Buhl R, Becher B (2011) IL-22 is produced by innate lymphoid cells and limits inflammation in allergic airway disease. PLoS One 6(7): e21799

27. Takahashi K, Hirose K, Kawashima S, Niwa Y, Wakashin H, Iwata A, Tokoyoda K, Renauld JC, Iwamoto I, Nakayama T, Nakajima H (2011) IL-22 attenuates IL-25 production by lung epithelial cells and inhibits antigen-induced eosinophilic airway inflammation. J Allergy Clin Immunol 128(5):1067-1076.e1-6

28. McGeachy MJ, Bak-Jensen KS, Chen Y, Tato CM, Blumenschein W, McClanahan T, Cua DJ (2007) TGF-beta and IL- 6 drive the production of IL-17 and IL-10 by T cells and restrain T (H)-17 cell-mediated pathology. Nat Immunol 8:1390-1397

29. Jovanovic DV, Di Battista JA, Martel-Pelletier J, Jolicoeur FC, He Y, Zhang M, Mineau F, Pelletier JP (1998) IL-17 stimulates the production and expression of proinflammatory cytokines, IL-beta and TNF-alpha, by human macrophages. J Immunol 160(7):3513-3521

30. Patera AC, Pesnicak L, Bertin J, Cohen JI (2002) Interleukin 17 modulates the immune response to vaccinia virus infection. Virology 299(1):56-63

31. Pelidou SH, Zou LP, Deretzi G, Oniding C, Mix E, Zhu J (2000) Enhancement of acute phase and inhibition of chronic phase of experimental autoimmune neuritis in Lewis rats by 
intranasal administration of recombinant mouse interleukin 17: potential immunoregulatory role. Exp Neurol 163(1):165-172

32. Andoh A, Fujino S, Bamba S, Araki Y, Okuno T, Bamba T, Fujiyama Y (2002) IL-17 selectively down-regulates TNF-alpha-induced RANTES gene expression in human colonic subepithelial myofibroblasts. J Immunol 169:1683-1687

33. Silverman MD, Zamora DO, Pan Y, Texeira PV, Baek SH, Planck SR, Rosenbaum JT (2003) Constitutive and inflammatory mediator-regulated fractalkine expression in human ocular tissues and cultured cells. Invest Ophthalmol Vis Sci 44:1608-1615

34. Kanda N, Koike S, Watanabe S (2005) IL-17 suppresses TNFalpha-induced CCL27 production through induction of COX-2 in human keratinocytes. J Allergy Clin Immunol 116:1144-1150

35. Schnyder B, Schnyder-Candrian S, Pansky A, Schmitz ML, Heim M, Ryff el B, Moser R (2005) IL-17 reduces TNF-induced Rantes and VCAM-1 expression. Cytokine 31:191-202

36. Tsaknaridis L, Spencer L, Culbertson N, Hicks K, LaTocha D, Chou YK, Whitham RH, Bakke A, Jones RE, Offner H, Bourdette DN, Vandenbark AA (2003) Functional assay for human CD4 + CD25+ Treg cells reveals an age-dependent loss of suppressive activity. J Neurosci Res 74:296-308

37. Zuany-Amorim C, Sawicka E, Manlius C, Le Moine A, Brunet LR, Kemeny DM, Bowen G, Rook G, Walker C (2002) Suppression of airway eosinophilia by killed Mycobacterium vaccae-induced allergen-specific regulatory T-cells. Nat Med 8(6):625-629

38. Gavett SH, Chen X, Finkelman F, Wills-Karp M (1994) Depletion of murine CD4+ T lymphocytes prevents antigen-induced airway hyperreactivity and pulmonary eosinophilia. Am J Respir Cell Mol Biol 10(6):587-593

39. Buenafe AC, Tsaknaridis L, Spencer L, Hicks KS, McMahan RH, Watson L, Culbertson NE, Latocha D, Wegmann K, Finn T et al (2004) Specificity of regulatory CD4 + CD25+ T cells for self-T cell receptor determinants. J Neurosci Res 76:129-140

40. Veldhoen M, Hocking RJ, Atkins CJ, Locksley RM, Stockinger B (2006) TGFbeta in the context of an inflammatory cytokine milieu supports de novo differentiation of IL-17-producing T cells. Immunity 24:179-189

41. Zenewicz LA, Yancopoulos GD, Valenzuela DM, Murphy AJ, Karow M, Flavell RA (2007) Interleukin-22 but not interleukin-17 provides protection to hepatocytes during acute liver inflammation. Immunity 27:647-659

42. Pan H, Hong F, Radaeva S, Gao B (2004) Hydrodynamic gene delivery of interleukin-22 protects the mouse liver from concanavalin A-, carbon tetrachloride-, and Fas ligand-induced injury via activation of STAT3. Cell Mol Immunol 1:43-49

43. Chang H, Hanawa H, Liu H, Yoshida T, Hayashi M, Watanabe R et al (2006) Hydrodynamicbased delivery of an interleukin-22-Ig fusion gene ameliorates experimental autoimmune myocarditis in rats. J Immunol 177:3635-3643

44. Sugimoto K, Ogawa A, Mizoguchi E, Shimomura Y, Andoh A, Bhan AK et al (2008) IL-22 ameliorates intestinal inflammation in a mouse model of ulcerative colitis. J Clin Invest 118:534-544

45. Michel ML, Keller AC, Paget C, Fujio M, Trottein F, Savage PB et al (2007) Identification of an IL-17-producing NK1.1(neg) iNKT cell population involved in airway neutrophilia. J Exp Med 204:995-1001

46. Schnyder-Candrian S, Quesniaux VF, Di Padova F, Maillet I, Noulin N, Couillin I et al (2005) Dual effects of p38 MAPK on TNF-dependent bronchoconstriction and TNF-independent neutrophil recruitment in lipopolysaccharide-induced acute respiratory distress syndrome. $\mathrm{J}$ Immunol 175:262-269

47. Palmqvist C, Wardlaw AJ, Bradding P (2007) Chemokines and their receptors as potential targets for the treatment of asthma. Br J Pharmacol 151:725-736

48. Nathan C (2006) Neutrophils and immunity: challenges and opportunities. Nat Rev Immunol 6:173-182 
49. Hellings PW, Kasran A, Liu Z, Vandekerckhove P, Wuyts A, Overbergh L et al (2003) Interleukin-17 orchestrates the granulocyte influx into airways after allergen inhalation in a mouse model of allergic asthma. Am J Respir Cell Mol Biol 28:42-50

50. Whittington HA, Armstrong L, Uppington KM, Millar AB (2004) Interleukin-22: a potential immunomodulatory molecule in the lung. Am J Respir Cell Mol Biol 31:220-226

51. Grünig G, Warnock M, Wakil AE, Venkayya R, Brombacher F, Rennick DM, Sheppard D, Mohrs M, Donaldson DD, Locksley RM, Corry DB (1998) Requirement for IL-13 independently of IL-4 in experimental asthma. Science 282(5397):2261-2263

52. Steinke JW (2004) Anti-interleukin-4 therapy. Immunol Allergy Clin North Am 24 (4):599-614

53. Wills-Karp M (1999) Immunologic basis of antigen-induced airway hyperresponsiveness. Annu Rev Immunol 17:255-281

54. Faour WH, Mancini A, He QW, Di Battista JA (2003) T-cell-derived interleukin-17 regulates the level and stability of cyclooxygenase-2 (COX-2) mRNA through restricted activation of the p38 mitogen-activated protein kinase cascade: role of distal sequences in the $3^{\prime}$-untranslated region of COX-2 mRNA. J Biol Chem 278(29):26897-26907

55. Yamazaki S, Muta T, Matsuo S, Takeshige K (2005) Stimulus-specific induction of a novel nuclear factor-kappaB regulator, IkappaB-zeta, via Toll/Interleukin-1 receptor is mediated by mRNA stabilization. J Biol Chem 280(2):1678-1687

56. Gonzalo JA, Lloyd CM, Kremer L, Finger E, Martinez-A C, Siegelman MH, Cybulsky M, Gutierrez-Ramos JC (1996) Eosinophil recruitment to the lung in a murine model of allergic inflammation. The role of $\mathrm{T}$ cells, chemokines and adhesion receptors. $\mathrm{J}$ Clin Invest 98 (10):2332-2345

57. Chvatchko Y, Proudfoot AE, Buser R, Juillard P, Alouani S, Kosco-Vilbois M, Coyle AJ, Nibbs RJ, Graham G, Offord RE, Wells TN (2003) Inhibition of airway inflammation by aminoterminally modified RANTES/CC chemokine ligand 5 analogues is not mediated through CCR3. J Immunol 171:5498-5506

58. Kawasaki S, Takizawa H, Yoneyama H, Nakayama T, Fujisawa R, Izumizaki M, Imai T, Yoshie O, Homma I, Yamamoto K, Matsushima K (2001) Intervention of thymus and activation-regulated chemokine attenuates the development of allergic airway inflammation and hyperresponsiveness in mice. J Immunol 166:2055-2062

59. Wang J, Homer RJ, Chen Q, Elias JA (2000) Endogenous and exogenous IL-6 inhibit aeroallergen-induced Th2 inflammation. J Immunol 165(7):4051-4061

60. Qiu Z, Fujimura M, Kurashima K, Nakao S, Mukaida N (2004) Enhanced airway inflammation and decreased subepithelial fibrosis in interleukin 6-deficient mice following chronic exposure to aerosolized antigen. Clin Exp Allergy 34(8):1321-1328

61. Kunikata T, Yamane H, Segi E, Matsuoka T, Sugimoto Y, Tanaka S, Tanaka H, Nagai H, Ichikawa A, Narumiya S (2005) Suppression of allergic inflammation by the prostaglandin E receptor subtype EP3. Nat Immunol 6(5):524-531

62. Tumas DB, Chan B, Werther W, Wrin T, Vennari J, Desjardin N, Shields RL, Jardieu P (2001) Anti-IgE efficacy in murine asthma models is dependent on the method of allergen sensitization. J Allergy Clin Immunol 107(6):1025-1033

63. Thompson JE, Phillips RJ, Erdjument-Bromage H, Tempst P, Ghosh S (1995) I kappaB-beta regulates the persistent response in a biphasic activation of NF-kappa B. Cell 80(4):573-582

64. Malek S, Chen Y, Huxford T, Ghosh G (2001) IkappaBbeta, but not IkappaBalpha, functions as a classical cytoplasmic inhibitor of NF-kappaB dimers by masking both NF-kappaB nuclear localization sequences in resting cells. J Biol Chem 276(48):45225-45235

65. Pickert G, Neufert C, Leppkes M, Zheng Y, Wittkopf N, Warntjen M, Lehr HA, Hirth S, Weigmann B, Wirtz S, Ouyang W, Neurath MF, Becker C (2009) STAT3 links IL-22signaling in intestinal epithelial cells to mucosal wound healing. J Exp Med 206(7):1465-1472

66. Nagalakshmi ML, Rascle A, Zurawski S, Menon S, de Waal Malefyt R (2004) Interleukin-22 activates STAT3 and induces IL-10 by colon epithelial cells. Int Immunopharmacol 4 (5):679-691 
67. Veldhoen M, Hirota K, Westendorf AM, Buer J, Dumoutier L, Renauld JC et al (2008) The aryl hydrocarbon receptor links $\mathrm{T}(\mathrm{H}) 17$-cell-mediated autoimmunity to environmental toxins. Nature 23:23

68. Dumoutier L, Louahed J, Renauld JC (2000) Cloning and characterization of IL-10-related T cell-derived inducible factor (IL-TIF), a novel cytokine structurally related to IL-10 and inducible by IL-9. J Immunol 164:1814-1819

69. Eyerich S, Eyerich K, Cavani A, Schmidt-Weber C (2010) IL-17 and IL-22: siblings, not twins. Trends Immunol 31(9):354-361

70. Park SJ, Lee YC (2010) Interleukin-17 regulation: an attractive therapeutic approach for asthma. Respir Res 11:78

71. Akkoc T, Akdis M, Akdis CA (2011) Update in the mechanisms of allergen-specific immunotherapy. Allergy Asthma Immunol Res 3(1):11-20

72. Eyerich S, Wagener J, Wenzel V, Scarponi C, Pennino D, Albanesi C, Schaller M, Behrendt H, Ring J, Schmidt-Weber CB, Cavani A, Mempel M, Traidl-Hoffmann C, Eyerich K (2011) IL22 and TNF- $\alpha$ represent a key cytokine combination for epidermal integrity during infection with Candida albicans. Eur J Immunol 41(7):1894-1901

73. Kabir S (2011) The role of interleukin-17 in the Helicobacter pylori induced infection and immunity. Helicobacter 16(1):1-8

74. Ma CS, Chew GY, Simpson N, Priyadarshi A, Wong M, Grimbacher B, Fulcher DA, Tangye SG, Cook MC (2008) Deficiency of Th17 cells in hyper IgE syndrome due to mutations in STAT3. J Exp Med 205(7):1551-1557

75. Aujla SJ, Chan YR, Zheng M, Fei M, Askew DJ, Pociask DA, Reinhart TA, McAllister F, Edeal J, Gaus K, Husain S, Kreindler JL, Dubin PJ, Pilewski JM, Myerburg MM, Mason CA, Iwakura Y, Kolls JK (2008) IL-22 mediates mucosal host defense against gram-negative bacterial pneumonia. Nat Med 14:275-281

76. Simonian PL, Wehrmann F, Roark CL, Born WK, O’Brien RL, Fontenot AP (2010) $\gamma \delta$ T cells protect against lung fibrosis via IL-22. J Exp Med 207(10):2239-2253 